\title{
Chemical composition of the Kobe meteorite; Neutron-induced prompt gamma ray analysis study
}

\author{
Y. OURA, ${ }^{1 *}$ M. EBIHARA, ${ }^{1}$ S. YONEDA ${ }^{2}$ and N. NAKAMURA ${ }^{3}$ \\ ${ }^{1}$ Department of Chemistry, Graduate School of Science, Tokyo Metropolitan University, \\ Hachioji, Tokyo 192-0397, Japan \\ ${ }^{2}$ Deparment of Science and Technology, The National Science Museum, Shinjuku-ku, Tokyo 169-0073, Japan \\ ${ }^{3}$ Department of Earth and Planetary Sciences, Faculty of Science, Kobe University, \\ Kobe, Hyogo 657-8501, Japan
}

(Received February 19, 2001; Accepted April 12, 2002)

\begin{abstract}
Neutron-induced prompt gamma ray analysis (PGA) was applied to several lump samples of the Kobe meteorites, along with powdered sample and separated chondrules, and a total of 15 elements $(\mathrm{H}, \mathrm{B}, \mathrm{Na}$, $\mathrm{Mg}, \mathrm{Al}, \mathrm{Si}, \mathrm{S}, \mathrm{Cl}, \mathrm{K}, \mathrm{Ca}, \mathrm{Ti}, \mathrm{Mn}, \mathrm{Fe}, \mathrm{Co}$ and $\mathrm{Ni}$ ) were determined non-destructively. Except for chondrule samples, uniformity in chemical composition is remarkable for most elements. Exceptions are $\mathrm{B}$ and $\mathrm{Cl}$, which appear to be heterogeneously distributed in the Kobe meteorite. Comparing $\mathrm{Mg} / \mathrm{Si}, \mathrm{Al} / \mathrm{Si}, \mathrm{Ca} / \mathrm{Si}$ and $\mathrm{Ti} / \mathrm{Si}$ ratios among carbonaceous chondrites (CI, CM, CV, CO and CK), CK chondrites are characterized by the highest $\mathrm{Mg} / \mathrm{Si}$ ratio. Abundances of $\mathrm{S}$ and $\mathrm{Zn}$ were observed to coincidently change among carbonaceous chondrites, as suggested by similar condensation temperatures. Boron abundances in CK are even lower than those for $\mathrm{S}$ and $\mathrm{Zn}$, being contrary to the prediction from thermodynamic calculation. For the classification of carbonaceous chondrites, we propose a S/Mn vs. Al/Mn diagram, on which individual groups of CI, CM, CV, CO and CK cluster with discrete locality. These three key elements are all determined for voluminous and irregularly shaped chondrite samples by PGA, showing that PGA has a great merit in analyzing new fall meteorites like Kobe.
\end{abstract}

\section{INTRODUCTION}

After a dispute about a classification of the Karoonda meteorite, CK group named after Karoonda was firmly acknowledged as a new group of carbonaceous chondrites after the detailed study by Kallemeyn et al. (1991), who studied large number of Antarctic CK's in addition to three non-Antarctic CK's (Karoonda, Maralinga and Ningqiang). Like Karoonda, Ningqiang is an observed fall, but it is compositionally resolvable from "normal" CK's represented by Karoonda. Maralinga is a weathered find from Australia. The Kobe meteorite fell in September, 1999 and was recognized as CK4 (Nakamura et al., 2000a), becoming the 4th non-Antarctic CK. Kobe was recovered soon after its fall and a scientific study was initiated immediately under the leadership of N. Nakamura of Kobe University (Nakamura et al., 2000b). The fall of Kobe was very fortunate for us because it is $\mathrm{CK}$, for which knowledge is still poor compared with other carbonaceous chondrite groups, and a consortium study was well organized. As a part of this consortium study, we performed to analyze the Kobe meteorite for chemical composition by using both neutron activation analysis (NAA) and photon activation analysis (PAA). Preliminary results of our study has been already reported by Nakamura et al. (2000a), and will be reported by Nakamura et al. (2002).

NAA has been extensively applied to meteorites for determining their chemical compositions. Methodologically, NAA is divided into two meth- 
ods, instrumental NAA (INAA) and radiochemical NAA (RNAA). INAA is performed by an aid of instruments having high resolution of gamma ray energy. Neutron-induced prompt gamma ray analysis (NIPGA or PGA) is a kind of INAA. In INAA, decay gamma rays emitted from radionuclides are used whereas prompt gamma rays released from an excited nuclei by absorbing neutrons are measured in PGA. By using PGA, several elements such as $\mathrm{H}, \mathrm{B}, \mathrm{Si}$, and $\mathrm{S}$, which cannot readily be determined for chondritic meteorites by conventional INAA, can be determined. The study of PGA has been gradually enhanced with installation of sophisticated neutron guide tubes at several nuclear reactors. PGA using a neutron beam extended from a research reactor through a guide tube has the advantage that it can be applied to samples of any size and shape because irradiation is performed outside the reactor (Nakahara et al., 2000). As residual activities in irradiated samples become negligible after an appropriate cooling interval, analyzed samples can be studied using other techniques (Ebihara and Oura, 2001). When applied to meteorite samples, we reported that PGA is a very useful analytical method for the determination of $\mathrm{Si}$ and $\mathrm{S}$ in addition to other major and trace elements (Latif et al., 1999). When compared with other analytical methods for rock samples, including chondritic meteorites, such as X-ray fluorescence, electronprobe microanalysis and secondary ion mass spectrometry, PGA is unique in being both a chemically and physically non-destructive analytical method for determining the chemical composition of geochemical and cosmochemical samples.

In this study, PGA was applied to the Kobe meteorite. We have reported preliminary chemical data for the fragment E (hereafter, Kobe E) obtained by INAA, instrumental photon activation analysis (IPAA) and PGA (Nakamura et al., 2000a). We analyzed fragment $C$ (Kobe $C$ ) in this work. Kobe $\mathrm{C}$ is a main mass (13.6 g) loaned for the consortium study. Kobe $\mathrm{C}$ was subdivided into several lumps. In addition to these lump samples, powdered sample prepared by roughly grinding two lump samples and chondrules separated from this ground sample were analyzed. By analyzing these samples non-destructively by PGA, we discuss the chemical homogeneity of Kobe, by comparing analytical data among several Kobe $\mathrm{C}$ samples (Kobe C's) and also between Kobe C's and Kobe E. As PGA presents Si data in addition to other major element contents, we describe chemical characteristics of major element composition for CK's. Also, considering that PGA is a nondestructive analytical method applicable to voluminous samples, the possibility for classification of bulky carbonaceous chondrite samples based only on PGA data is discussed.

\section{EXPERIMENTAL}

\section{Sample preparation}

We analyzed four lumps (C-main, C-1, C-2 and C-4a), two chondrules (C-3-2ch) and one powder sample (C-3mix-3) taken from fragment $\mathrm{C}$ of the Kobe meteorite. As each chondrule of C-3-2ch weighs less than $5 \mathrm{mg}$, two chondrules were combined as one sample $(6.37 \mathrm{mg}$ in total) for analysis. Both are barred olivine chondrules. Parts of C-main and C-1 samples were covered with thin fusion crust, whereas other lump samples (C-2 and C-4a) have no fusion crust. The fusion crust was not removed for analysis. The powdered sample, $\mathrm{C}-3 \mathrm{mix}$, was prepared by crushing the interior portion (C-3 and C-3-2) (weighing $0.640 \mathrm{~g}$ and $0.273 \mathrm{~g}$, respectively) of fragment $\mathrm{C}$, having no fusion crust. Several chondrules including two chondrules $(\mathrm{C}-3-2 \mathrm{ch})$ were separated during the preparation of $\mathrm{C}-3 \mathrm{mix}$. The sample $\mathrm{C}-3 \mathrm{mix}-3$ is an aliquant of C-3mix. All lump samples except $\mathrm{C}$-main were lightly rinsed twice with high purity ethyl alcohol before analysis. In addition to Kobe samples, the Maralinga carbonaceous chondrite, tentatively classified as CK by Kallemeyn et al. (1991), was analyzed for comparison. We used a portion of the Maralinga powdered sample, which was prepared by grinding $2.5 \mathrm{~g}$ of Maralinga chips in an agate mortar. Sample descriptions are given in Table 1. 


\section{Irradiation and measurement}

All Kobe and Maralinga samples were analyzed by PGA. Powdered samples (Kobe C3mix-3 and Maralinga) were also analyzed by instrumental photon activation analysis (IPAA).

$P G A$ The samples were put into thin fluorinated ethylene propylene resin film bags and were irradiated at the prompt gamma ray analyzing system (Yonezawa et al., 1993) for about 2 hours by a cold neutron beam (flux: $1.4 \times 10^{8} \mathrm{n} \mathrm{cm}^{-2} \mathrm{~s}^{-1}$ ) guided out from a research reactor JRR-3M at the Japan Atomic Energy Research Institute. The neu-

Table 1. Descriptions of the Kobe meteorite samples analyzed in this work

\begin{tabular}{llcc}
\hline Name & Form & Rough size [mm] & Weight [g] \\
\hline C-main & lump & $10 \times 20 \times 10$ & 2.7656 \\
C-1 & lump & $10 \times 7 \times 7$ & 0.9785 \\
C-2 & lump & $10 \times 8 \times 3$ & 0.4723 \\
C-4a & lump & $10 \times 8 \times 6$ & 0.5462 \\
C-3mix-3 & powder & powder & 0.04032 \\
C-3-2ch & chondrule & 1 and $1.5 \emptyset^{(\mathrm{b})}$ & 0.00637 \\
\hline
\end{tabular}

${ }^{(a)}$ Consists of 2 barred olivine chondrules.

${ }^{(b)}$ Diameter. tron beam is collimated to the size of $20 \mathrm{~mm} \times 20$ $\mathrm{mm}$ at the entrance of a sample box. Prompt gamma rays were detected by a Ge detector coupled to a $16 \mathrm{k}$ channel pulse-height analyzer. The Ge detector is surrounded with bismuth germanate (BGO) detectors so that signals due to Compton gamma rays induced by high-energy prompt gamma rays are effectively suppressed by measuring anticoincident signals from $\mathrm{Ge}$ and $\mathrm{BGO}$ detectors.

Absolute values of elemental contents were obtained for powder samples (C-3mix-3 and Maralinga) and chondrules (C-3-2ch) by using JB1 (a geological standard rock issued by the Geological Survey of Japan) and the Allende carbonaceous chondrite (a meteorite reference sample prepared by the Smithsonian Institution) (Jarosewich et al., 1987) as reference standards. Chemical reagents, $\mathrm{NH}_{4} \mathrm{Cl}$ and $\mathrm{Na}_{2} \mathrm{SO}_{4}$ also were used as reference standards for the determination of $\mathrm{H}$ and $\mathrm{Cl}$, and $\mathrm{S}$, respectively. In addition to these absolute contents, contents relative to $\mathrm{Si}$ also were determined by applying the internal monostandard method (Sueki et al., 1996; Latif, 2000) for four lump samples (C-main, C-1, C-2 and C-

Table 2. Reproducibility of PGA data for the Smithsonian Allende reference obtained by using the comparison method $^{(a)}$

\begin{tabular}{|c|c|c|c|c|c|c|c|c|}
\hline & $\# 1$ & $\# 2$ & $\# 3$ & $\# 4$ & $\# 5$ & Average & $\operatorname{RSD}[\%]^{(\mathrm{b})}$ & lit. ${ }^{(c)}$ \\
\hline $\mathrm{H}[\%]$ & $0.0380(37)$ & $0.0341(38)$ & $0.0394(40)$ & $0.419(42)$ & $0.0394(42)$ & 0.0386 & 7.4 & \\
\hline $\mathrm{B}$ [ppm] & $1.5(4)$ & $1.2(3)$ & $2.0(3)$ & $1.3(3)$ & $2.5(4)$ & 1.7 & 36 & \\
\hline $\mathrm{Na}[\%]$ & $0.26(4)$ & $0.38(4)$ & $0.33(4)$ & $0.35(4)$ & $0.38(5)$ & 0.34 & 15 & 0.341 \\
\hline $\mathrm{Al}[\%]$ & $1.68(22)$ & $1.81(21)$ & $1.66(19)$ & $1.75(19)$ & $1.55(20)$ & 1.69 & 5.8 & 1.736 \\
\hline $\mathrm{Si}[\%]$ & $15.9(9)$ & $17.6(10)$ & $15.9(9)$ & $16.0(9)$ & $1.69(10)$ & 16.4 & 4.6 & 16.02 \\
\hline $\mathrm{S}[\%]$ & $2.15(10)$ & $2.19(11)$ & $2.41(11)$ & $2.21(10)$ & $2.38(12)$ & 2.27 & 5.3 & 2.1 \\
\hline $\mathrm{Cl}$ [ppm] & $432(38)$ & $360(45)$ & $355(32)$ & $345(35)$ & $369(39)$ & 372 & 9.2 & \\
\hline $\mathrm{Ca}[\%]$ & $1.49(16)$ & $1.83(16)$ & $1.69(15)$ & $1.38(15)$ & $1.64(18)$ & 1.61 & 11 & 1.84 \\
\hline $\mathrm{Ti}[\%]$ & $0.083(10)$ & $0.10(1)$ & $0.094(10)$ & $0.091(10)$ & $0.079(11)$ & 0.089 & 9.5 & 0.0899 \\
\hline $\mathrm{Cr}[\%]$ & $0.396(25)$ & $0.393(25)$ & $0.455(26)$ & $0.362(23)$ & $0.370(39)$ & 0.395 & 9.3 & 0.363 \\
\hline $\operatorname{Mn}[\%]$ & $0.132(23)$ & $0.145(24)$ & $0.144(24)$ & $0.141(25)$ & $0.156(27)$ & 0.144 & 6.2 & 0.147 \\
\hline $\mathrm{Fe}[\%]$ & $21.8(16)$ & $22.3(16)$ & $21.8(15)$ & $22.0(15)$ & $21.7(15)$ & 21.9 & 1.2 & 23.57 \\
\hline Co [\%] & $0.0715(78)$ & $0.0812(77)$ & $0.0700(72)$ & $0.0723(71)$ & $0.0708(76)$ & 0.0732 & 6.2 & 0.0661 \\
\hline $\mathrm{Ni}[\%]$ & $1.37(8)$ & $1.33(8)$ & $1.33(8)$ & $1.33(9)$ & $1.27(69)$ & 1.33 & 2.6 & 1.42 \\
\hline
\end{tabular}

${ }^{(a)}$ The figures in parentheses are statistical errors $(1 \sigma)$, corresponding to the last digit( $\left.s\right)$; for example, $12.3 \pm 4.5$ is expressed as 12.3(45).

${ }^{(b)}$ Relative standard deviation of 5 determinations, not including statistical errors associated with individual determinations.

${ }^{(c)}$ Recommended values in Jarosewich et al. (1987). 
4a), which are voluminous and irregularly shaped. In determining absolute contents, an error due to the fluctuation of neutron beam flux (normally, $2.5 \%$ in one day; Yonezawa et al., 1993) was not considered. Such an error is not involved in the internal mono-standard method.

As PGA data weigh heavily in the later discussion, it may be suitable to describe the quality of PGA data here. In Table 2, replicate results of the Smithsonian Allende reference sample by PGA are summarized. Analyses were repeated five times for the same sample $(256.6 \mathrm{mg})$ by using thermal neutron beam (flux: $2.4 \times 10^{7} \mathrm{n} \mathrm{cm}^{-2} \mathrm{~s}^{-1}$ ). In the table, average values and their relative standard deviation (RSD; $1 \sigma$ ) for 14 elements are shown, along with individual analytical values and corresponding literature data. It is noticed that all the elements except $\mathrm{B}$ and $\mathrm{Na}$ (and $\mathrm{Ca}$ ) were determined within 10\% RSD. Except for H, B and $\mathrm{Cl}$, whose recommendation values are not given in Jarosewich et al. (1987), our PGA values are consistent with the recommended values by Jarosewich et al. (1987) with a relative ratio of $1.008 \pm 0.083(1 \sigma)$. The value of RSD for each element is roughly correlated with the intensity of its prompt gamma ray; for $\mathrm{Fe}$, these values are $1.2 \%$ and $0.171 \mathrm{cps}$, respectively, whereas $9.5 \%$ and $0.0232 \mathrm{cps}$ for Ti. Exceptionally large RSD values (15\% and $36 \%$ ) were calculated for $\mathrm{Na}$ and $\mathrm{B}$, respectively. For $\mathrm{Na}$, a value of the first measurement seems to be erratically too small. Except this value, the rest of data yield a RSD of $2.4 \%$. Nevertheless, no plausible reasons for rejecting the first value can be presented. The prompt gamma peak of B is very unique, with not a normal gaussian but a trapezoid shape, and is overlapped by prompt gamma ray peaks of $\mathrm{Na}$ and $\mathrm{Co}$. Samples having relatively high Co/B ratios like chondritic meteorites need large corrections due to such an overlapping of prompt gamma rays.

IPAA Two powdered samples (Kobe C-3mix-3 and Maralinga) were analyzed by IPAA. About $50 \mathrm{mg}$ of each sample was wrapped with Al foil and irradiated by bremsstrahlung gamma ray (end point energy: $30 \mathrm{MeV}$ ) generated by an electron linear accelerator at the Laboratory of Nuclear Science,
Tohoku University. Samples were irradiated successively for $30 \mathrm{~min}$ and $5 \mathrm{~h}$. After each irradiation, samples were measured for gamma rays several times with different cooling intervals. Both JB-1 and the Smithsonian Allende powder samples were used as references for the determination of elemental contents. More detailed descriptions of the IPAA procedure for meteorite samples appear in Ebihara et al. (2000).

\section{RESUlTS AND DISCUSSION}

Intercomparison of analytical data among Kobe meteorite samples

In PGA, a total of 15 elements were determined; H, B, Na, Mg, Al, Si, S, Cl, K, Ca, Ti, Mn, $\mathrm{Fe}, \mathrm{Co}, \mathrm{Ni}$. Analytical data of these elements for Kobe samples and Maralinga are summarized in Table 3. In Table 3, we show both Si-normalized weight ratios for lump samples of the Kobe fragment $\mathrm{C}$ obtained by the internal mono-standard method of PGA (Table 3a) and absolute contents for non-lump samples of Kobe $\mathrm{C}$ and Maralinga determined by the comparison method (Table $3 b$ ). Table 4 shows data for powdered samples (Kobe C-3mix-3 and Maralinga) obtained by IPAA. Errors shown in parentheses in Tables 3 and 4 are due to radioactivity counting statistics $(1 \sigma)$. It may be worth remarking that several light elements such as $\mathrm{H}, \mathrm{B}, \mathrm{Si}$ and $\mathrm{S}$ can be non-destructively determined by PGA for lump as well as powder samples. As further quantification is needed for the determination of $\mathrm{H}, \mathrm{H}$ contents may be regarded as information values for this study. The powdered sample, C-3mix-3, was analyzed by PGA and IPAA. As shown in Tables 3 and 4, data for elements determined by both methods are reasonably consistent. Considering that IPAA (and INAA) normally involves several (at least two times) successive irradiations and gamma ray countings, PGA has a great merit in determining bulk chemical composition of rock samples including chondritic meteorites, because it requires only a single irradiation/counting cycle for each sample. 
Table 3(a). Elemental weight ratios $(S i=1)$ of 4 lump samples from Kobe fragment $C$ determined by PGA coupled with the internal mono standard method ${ }^{(a)}$

\begin{tabular}{lcccccc}
\hline & C-main & C-1 & C-2 & C-4a & \multicolumn{2}{c}{ Mean $^{(\text {b }) ~}$} \\
\cline { 3 - 6 } & & & & ratio & absolute $^{(\mathrm{c})}$ \\
\hline $\mathrm{H}^{(\mathrm{d})}$ & $0.000554(35)$ & $0.000827(60)$ & $0.000229(53)$ & $0.000733(56)$ & $0.00059(26)$ & $0.0089(40)$ \\
$\mathrm{B}$ & $<3 \times 10^{-7}$ & $<4 \times 10^{-7}$ & $<5 \times 10^{-7}$ & $<4 \times 10^{-7}$ & & \\
$\mathrm{Na}$ & $0.013(3)$ & $0.0158(16)$ & $0.0178(5)$ & $0.011(4)$ & $0.0146(28)$ & $0.22(4)$ \\
$\mathrm{Mg}$ & $0.909(35)$ & $1.01(4)$ & $0.959(46)$ & $0.888(40)$ & $0.942(55)$ & $14.2(8)$ \\
$\mathrm{Al}$ & $0.0870(28)$ & $0.0876(38)$ & $0.0847(41)$ & $0.0834(31)$ & $0.0857(20)$ & $1.29(3)$ \\
$\mathrm{Si}$ & 1 & 1 & 1 & 1 & 1 & 15.1 \\
$\mathrm{~S}$ & $0.0947(33)$ & $0.0965(34)$ & $0.114(4)$ & $0.100(3)$ & $0.101(9)$ & $1.53(14)$ \\
$\mathrm{Cl}$ & $0.00185(7)$ & $0.00154(6)$ & $0.00180(8)$ & $0.00174(8)$ & $0.00173(14)$ & $0.0261(12)$ \\
$\mathrm{K}$ & $0.00162(23)$ & $0.0018(3)$ & $0.0018(4)$ & $0.00168(24)$ & $0.00172(8)$ & $0.0260(12)$ \\
$\mathrm{Ca}$ & $0.111(4)$ & $0.101(4)$ & $0.106(5)$ & $0.112(48)$ & $0.108(5)$ & $1.63(8)$ \\
$\mathrm{Ti}$ & $0.00529(12)$ & $0.00529(16)$ & $0.00546(20)$ & $0.00546(17)$ & $0.00538(10)$ & $0.0812(15)$ \\
$\mathrm{Mn}$ & $0.00854(31)$ & $0.00900(38)$ & $0.00875(43)$ & $0.00876(37)$ & $0.00876(19)$ & $0.132(3)$ \\
$\mathrm{Fe}$ & $1.48(3)$ & $1.53(4)$ & $1.56(4)$ & $1.56(5)$ & $1.53(4)$ & $23.1(6)$ \\
$\mathrm{Co}$ & $0.00447(16)$ & $0.00450(16)$ & $0.00527(21)$ & $0.00469(17)$ & $0.00473(37)$ & $0.0714(56)$ \\
$\mathrm{Ni}$ & $0.0882(19)$ & $0.0946(24)$ & $0.105(3)$ & $0.0987(25)$ & $0.0966(71)$ & $1.46(11)$ \\
\hline
\end{tabular}

\footnotetext{
${ }^{(a)}$ The figures in parentheses are statistical errors $(1 \sigma)$, corresponding to the last digit(s). (Also see footnote (a) for Table 2.) ${ }^{(b)}$ Mean values of 4 lump samples.

${ }^{(c)}$ Si content was assumed to be equal to that in C-3mix-3 (15.1\%). Units for each element are the same as those in Table 3(b).

${ }^{(d)}$ Information values.
}

Table 3(b). Absolute elemental concentrations of powder and chondrule samples from Kobe fragment $C$ and Maraling a powder determined by PGA coupled with the comparison method ${ }^{(a)}$

\begin{tabular}{lccc}
\hline & C-3mix-3 & C-3-2ch & Maralinga \\
\hline $\mathrm{H}[\%]^{(b)}$ & $0.014(6)$ & $<0.08$ & $-^{(\mathrm{c})}$ \\
$\mathrm{B}[\mathrm{ppm}]$ & $<0.2$ & $<9$ & $2.7(4)$ \\
$\mathrm{Na}[\%]$ & $0.279(39)$ & $0.283(40)$ & $0.304(32)$ \\
$\mathrm{Mg}[\%]$ & $15.7(45)$ & $24.2(62)$ & $14.1(7)$ \\
$\mathrm{Al}[\%]$ & $1.49(17)$ & $1.94(68)$ & $1.69(6)$ \\
$\mathrm{Si}[\%]$ & $15.1(7)$ & $16.3(11)$ & $15.7(2)$ \\
$\mathrm{S}[\%]$ & $1.88(8)$ & $0.27(15)$ & $0.07(1)$ \\
$\mathrm{Cl}[\%]$ & $0.0262(30)$ & $0.025(17)$ & $0.0246(2)$ \\
$\mathrm{K}[\%]$ & $0.0632(184)$ & $<0.2$ & $0.0520(45)$ \\
$\mathrm{Ca}[\%]$ & $1.44(11)$ & $0.71(22)$ & $3.32(1)$ \\
$\mathrm{Ti}[\%]$ & $0.0815(58)$ & $0.157(13)$ & $0.0757(2)$ \\
$\mathrm{Mn}[\%]$ & $0.153(15)$ & $0.220(40)$ & $0.111(2)$ \\
$\mathrm{Fe}[\%]$ & $23.2(10)$ & $28.0(11)$ & $22.8(2)$ \\
$\mathrm{Co}[\%]$ & $0.072(13)$ & $0.11(2)$ & $0.0408(2)$ \\
$\mathrm{Ni}[\%]$ & $1.51(7)$ & $0.845(102)$ & $0.43(1)$ \\
\hline
\end{tabular}

${ }^{(a)}$ The figures in parentheses are statistical errors $(1 \sigma)$, corresponding to the last digit(s). (Also see footnote (a) for Table 2.)

${ }^{(b)}$ Information values.

${ }^{(c)}$ Not analysed.
Relative abundances (by weight) of elements normalized to $\mathrm{Si}$ values and $\mathrm{CI}$ chondrite abundances are shown in Fig. 1 for Kobe samples, including Kobe E (Nakamura et al., 2002). These data were all obtained by PGA. CI chondrite averages compiled by Anders and Grevesse (1989) are used for normalization. Except for chondrule samples, chemical compositions are considerably uniform in Kobe $\mathrm{C}$ samples. For refractory and siderophile elements, uniformity is remarkable among Kobe C's. Kobe E shows several small deviations from Kobe $\mathrm{C}$ (enrichment of $\mathrm{Al}$ and depletion of $\mathrm{Ni}$ and $\mathrm{Fe}$ ) but such deviations are marginal. Volatile elements show somewhat larger scatter in elemental contents even in Kobe $\mathrm{C}$. The $\mathrm{K}$ content in C-3mix-3 is 2.5 times larger and the $\mathrm{H}$ content in $\mathrm{C}-2$ is 3 times smaller than their mean values of the other Kobe C's. Kobe E data for volatile elements deviate slightly from those of Kobe C's, but their variability in Kobe E is similar to those for refractory and siderophile elements in Kobe C. 
Table 4. Elemental concentrations in Kobe C-3mix-3 and Maralinga determined by IPAA ${ }^{(a)}$

\begin{tabular}{|c|c|c|c|c|c|c|c|c|}
\hline & $\mathrm{Na}[\%]$ & $\mathrm{Mg}[\%]$ & $\mathrm{Si}[\%]$ & $\mathrm{K}[\%]$ & $\mathrm{Ca}[\%]$ & $\mathrm{Ti}[\%]$ & $\mathrm{Cr}[\%]$ & Mn [\%] \\
\hline C-3mix-3 & $0.289(10)$ & $15.4(7)$ & $16.5(9)$ & - $^{\text {(b) }}$ & $1.47(3)$ & $0.0667(53)$ & $0.365(6)$ & $0.14(2)$ \\
\hline \multirow[t]{2}{*}{ Maralinga } & $0.294(8)$ & $15.1(9)$ & $15.0(8)$ & $0.08(7)$ & $3.33(5)$ & $0.0906(42)$ & $0.354(2)$ & $0.16(2)$ \\
\hline & $\mathrm{Fe}[\%]$ & Co [ppm] & $\mathrm{Ni}[\%]$ & $\mathrm{Zn}[\mathrm{ppm}]$ & $\mathrm{Rb}[\mathrm{ppm}]$ & $\mathrm{Sr}[\mathrm{ppm}]$ & $\mathrm{Y}[\mathrm{ppm}]$ & $\mathrm{Zr}[\mathrm{ppm}]$ \\
\hline C-3mix -3 & $24.0(1)$ & $628(17)$ & $1.51(4)$ & $75.3(42)$ & $1.48(18)$ & $13.2(17)$ & 2.81(19) & $8.74(54)$ \\
\hline Maralinga & $22.7(7)$ & $423(7)$ & $0.53(1)$ & $56.0(65)$ & $1.1(4)$ & $23.8(21)$ & $3.6(5)$ & $5.4(3)$ \\
\hline
\end{tabular}

${ }^{(a)}$ The figures in parentheses are statistical errors $(1 \sigma)$, corresponding to the last digit(s). (Also see footnote (a) for Table 2.)

${ }^{(b)}$ Not analysed.

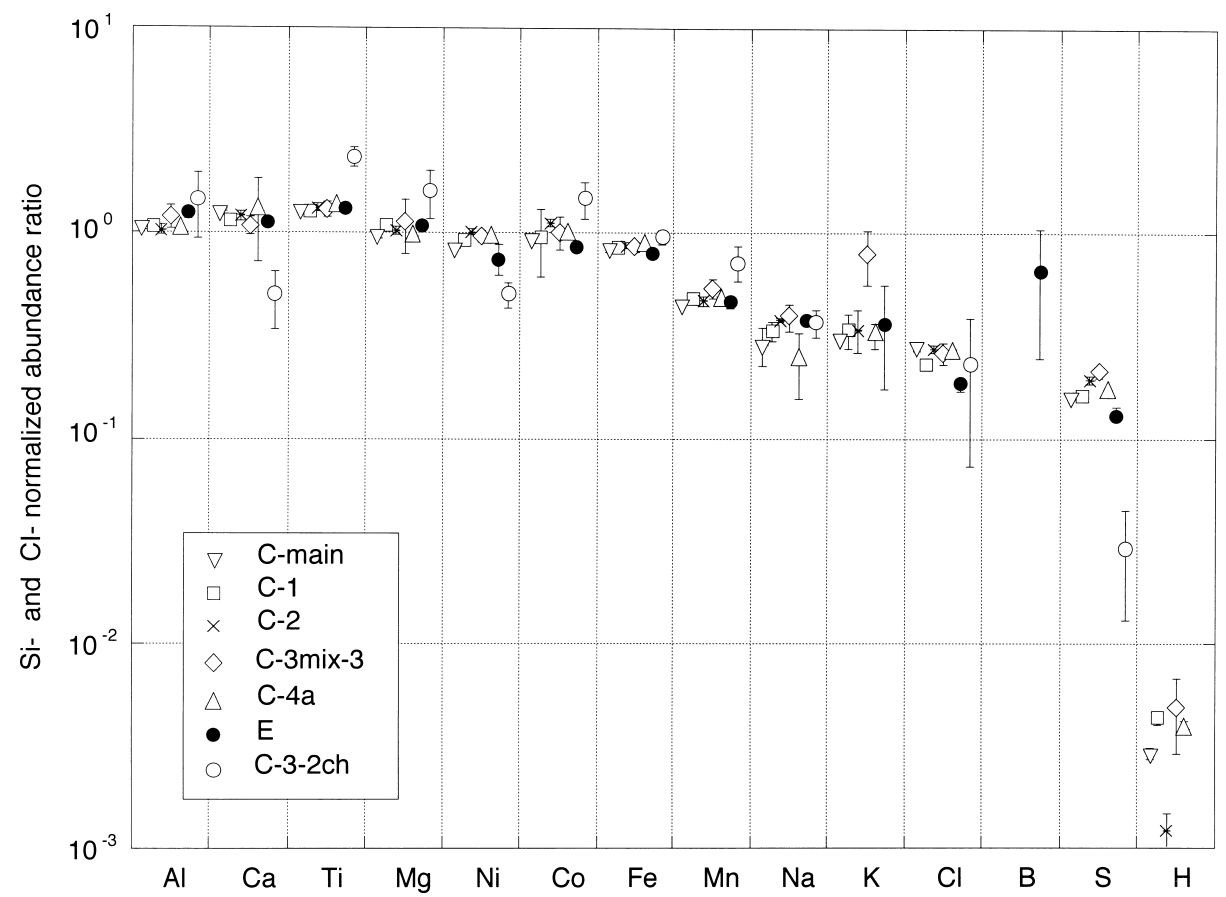

Fig. 1. Si- and CI-normalized elemental ratios in Kobe meteorite samples. Values for Kobe C obtained by PGA are from this work and those of Kobe E are from Nakamura et al. (2002).

Hirota et al. (2000) reported that REE abundances in Kobe-E were 1.5 to 2 times higher than those of Kobe C (an aliquant of C-3mix) and that the CI-normalized REE abundance pattern of Kobe-E was not chondritic. We did not confirm any element which has a positive correlation with REE between Kobe C-3mix and Kobe E. However, we observed a depletion of $\mathrm{Rb}$ by a factor of 2.5 in Kobe E compared with Kobe C-3mix-3,
Maralinga and Karoonda by IPAA (Nakamura et al., 2002). As mentioned above, $\mathrm{K}$ content in Kobe C-3mix-3 is 2 times higher than those for Kobe E and other Kobe C. Sodium does not seem to be variable in contents among Kobe $\mathrm{E}$ and Kobe $\mathrm{C}$. Apparently, individual alkaline elements $(\mathrm{Na}, \mathrm{K}$ and $\mathrm{Rb}$ ) have their own favorite phases and these phases are heterogeneously distributed in the Kobe meteorite. 
Boron is one of the most sensitive elements to PGA. Boron in Kobe-E was determined to be $0.89 \pm 0.55 \mathrm{ppm}$, which corresponds to $\mathrm{B} / \mathrm{Si}=$ $5.3 \times 10^{-6}$ (Nakamura et al., 2002), whereas only upper limits $\left(\mathrm{B} / \mathrm{Si}=3 \times 10^{-7}-5 \times 10^{-7}\right)$ were obtained for all Kobe $\mathrm{C}$ samples in spite of using larger amounts for Kobe $\mathrm{C}$ than for Kobe-E. Boron is highly prone to contamination (Curtis et al., 1980). Compared with Kobe E, Kobe C's, especially lump samples, were prepared with great care to minimise any possible contamination. Thus, it is probable that the higher $\mathrm{B}$ abundance in Kobe$\mathrm{E}$ is due to contamination. If so, it is truly difficult to obtain accurate contents of B in meteorite samples, considering that Kobe is a fall and that Kobe-E was prepared shortly after its fall. Of course, the possibility of heterogeneous distribution of B in Kobe, at least between Kobe C's and Kobe E, cannot be ruled out.

Halogens are known to be heterogeneously distributed in chondritic meteorites. In fact, Zolensky et al. (1999) found halite crystals in the Monahans ordinary chondrite. Among halogens, chlorine can be nondestructively determined in chondritic meteorites by PGA. As shown in Fig. 1 , chlorine contents in Kobe C's are fairly constant. Kobe $\mathrm{E}$ has a somewhat lower $\mathrm{Cl}$ content than Kobe C. In ordinary chondrites, chlorine is partly present in water-soluble form(s) (Kato et al., 2000). A smaller $\mathrm{Cl}$ content in Kobe E cannot be explained in terms of leaching of $\mathrm{Cl}$; Kobe $\mathrm{E}$ was prepared without washing the surface, whereas lumps of Kobe $\mathrm{C}$ were all rinsed with alcohol. Presumably, $\mathrm{Cl}$ is heterogeneously distributed in the Kobe chondrite, just as in ordinary chondrites.

Kobe C-3-2ch consists of two barred olivine chondrules, each of which weighs less than $5 \mathrm{mg}$. Even for such a small sample, PGA can be effectively applied, yielding abundance data for $12 \mathrm{el}$ ements, although large errors are involved in elemental contents for some of them because of poor counting statistics. Kobe C-3-2ch is characterized by high $\mathrm{Ti}$ and low $\mathrm{S}$ contents compared with those for other Kobe C. The Co/Ni ratio for Kobe C-3$2 \mathrm{ch}$ is apparently higher than the average for other
C-3's. Nickel and Co are hardly fractionated from each other during condensation, because their condensation temperatures are almost equal (1351 K for Co and $1354 \mathrm{~K}$ for $\mathrm{Ni}$; Wasson, 1985). Kong and Ebihara (1997) observed that $\mathrm{Co} / \mathrm{Ni}$ ratios in metals of unequilibrated ordinary chondrites are significantly lower than those for the bulk chondrites and inferred that such a fractionation must have occurred when metals and chondrules were formed by melting of the precursor material with essentially CI chemical composition. In fact, higher $\mathrm{Co} / \mathrm{Ni}$ ratios than that of the bulk was observed in the Ni-poor chondrules from the highly unequilibrated chondrite (Semarkona) (Grossman and Wasson, 1985), being complementary to low $\mathrm{Co} / \mathrm{Ni}$ ratios in metals. As metals are scarcely present in Kobe, high $\mathrm{Co} / \mathrm{Ni}$ ratios in chondrules must be compensated by low $\mathrm{Co} / \mathrm{Ni}$ ratios in some constituent minerals, presumably sulfides, in matrix. As expected, iron contents are not variable in Kobe samples, including Kobe C-3-2ch.

\section{Comparison of analytical data among CK mete- orites}

CI- and Si-normalized elemental abundances in Kobe and other $\mathrm{CK}$ chondrites including Maralinga are shown in Fig. 2. "Kobe mean" in Fig. 2 was obtained by averaging data for five Kobe C samples (this work) and those for Kobe $\mathrm{E}$ (Nakamura et al., 2002). Wiik (1969) and Jarosewich (1990) determined chemical compositions of Karoonda and two Antarctic CK's (EET 87860 and EET 87009), respectively, by wet chemical analysis. Elemental abundances of Karoonda (Nakamura et al., 2002) were obtained by PGA, IPAA, and INAA. We plotted only such data as having Si values in Fig. 2. Generally, the abundance pattern for Kobe is similar to those for other CK chondrites, although a small deviation in elemental abundances can be seen among CK's; the deviation is smaller for refractory lithophile and siderophile elements than that for volatile elements. Among CK's, Maralinga tends to show large scattering for several elements; $\mathrm{Ni}, \mathrm{Co}$ and $\mathrm{S}$ are depleted whereas $\mathrm{Ca}, \mathrm{K}$ and $\mathrm{B}$ are enriched. Considering that Maralinga was found in Australia 


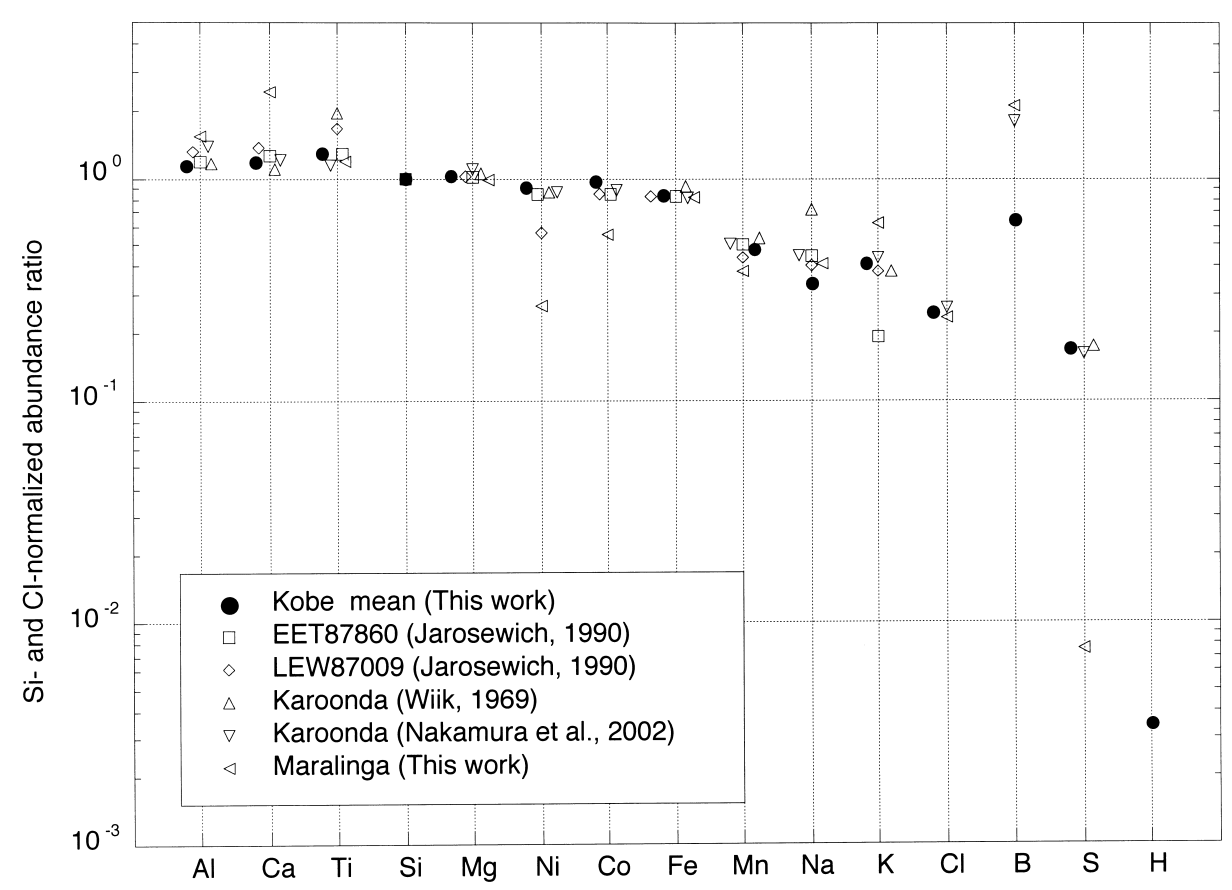

Fig. 2. Si- and CI-normalized abundance diagram of CK chondrites. Closed circles designated for Kobe mean are averages for Kobe C-main, C-1, C-2, C-4a, and C-3mix-3 in this work, and Kobe E by Nakamura et al. (2002).

and is heavily weathered, depletion of $\mathrm{Ni}$ and $\mathrm{Co}$, and $\mathrm{S}$ must have been caused by selective dissolution of metal and sulfide phases, respectively. Similar characteristic depletion of chalcophile elements such as $\mathrm{S}$ and Se were also confirmed in weathered $\mathrm{R}$ chondrites (unpublished data). Enrichment of $\mathrm{B}$ must be due to terrestrial contamination as already discussed. Higher $\mathrm{K}$ and $\mathrm{Ca}$ abundances may be caused by either terrestrial contamination or heterogeneous distribution of specific phase(s) in which alkali and alkaline earth elements are relatively enriched.

As we could determine Si together with Al, Ca, $\mathrm{Mg}$ and $\mathrm{Ti}$ as refractory lithophiles for a single specimen by PGA, we can compare relative abundances of these elements in carbonaceous chondrites including CK's. Figure 3 shows relative atomic ratios of $\mathrm{Al} / \mathrm{Si}, \mathrm{Ca} / \mathrm{Si}, \mathrm{Mg} / \mathrm{Si}$ and $\mathrm{Ti} /$ $\mathrm{Si}$ in carbonaceous chondrites. We used mean values for CI, CM, CO and CV estimated by Wasson and Kallemeyn (1988). For CK values, individual data from this study and literature (Wiik, 1969;
Jarosewich, 1990; Nakamura et al., 2002) (shown by open circles) and their mean values (shown by closed circle) are plotted in Fig. 3. In calculating mean values for $\mathrm{CK}$, data outside $1 \sigma$ ( $\sigma$ : relative standard deviation) of grand means are not used. (Literature values used for calculation are shown in Appendix.) These ratios for CK are firstly compared with those of other carbonaceous chondrites in this study. It is noticed that $\mathrm{Al} / \mathrm{Si}, \mathrm{Ca} / \mathrm{Si}$ and $\mathrm{Ti} /$ $\mathrm{Si}$ ratios change similarly in carbonaceous chondrites, having the highest values in $\mathrm{CV}$ and the lowest values in CI. On the other hand, the change of $\mathrm{Mg} / \mathrm{Si}$ ratios is completely different from those ratios; $\mathrm{CK}$ has the highest ratio, with CM-CO having the lowest. Apparently, the difference in volatility of elements concerned causes these two distinct changes. Thus, CK chondrites are characterized by the highest $\mathrm{Mg} / \mathrm{Si}$ ratio in carbonaceous chondrites. Kallemeyn et al. (1991) analyzed six CK chondrites by INAA and found that $\mathrm{Mg}$ - and CI-normalized abundances of refractory lithophile elements like $\mathrm{Ca}, \mathrm{Al}$ and $\mathrm{Ti}$ in CK's 

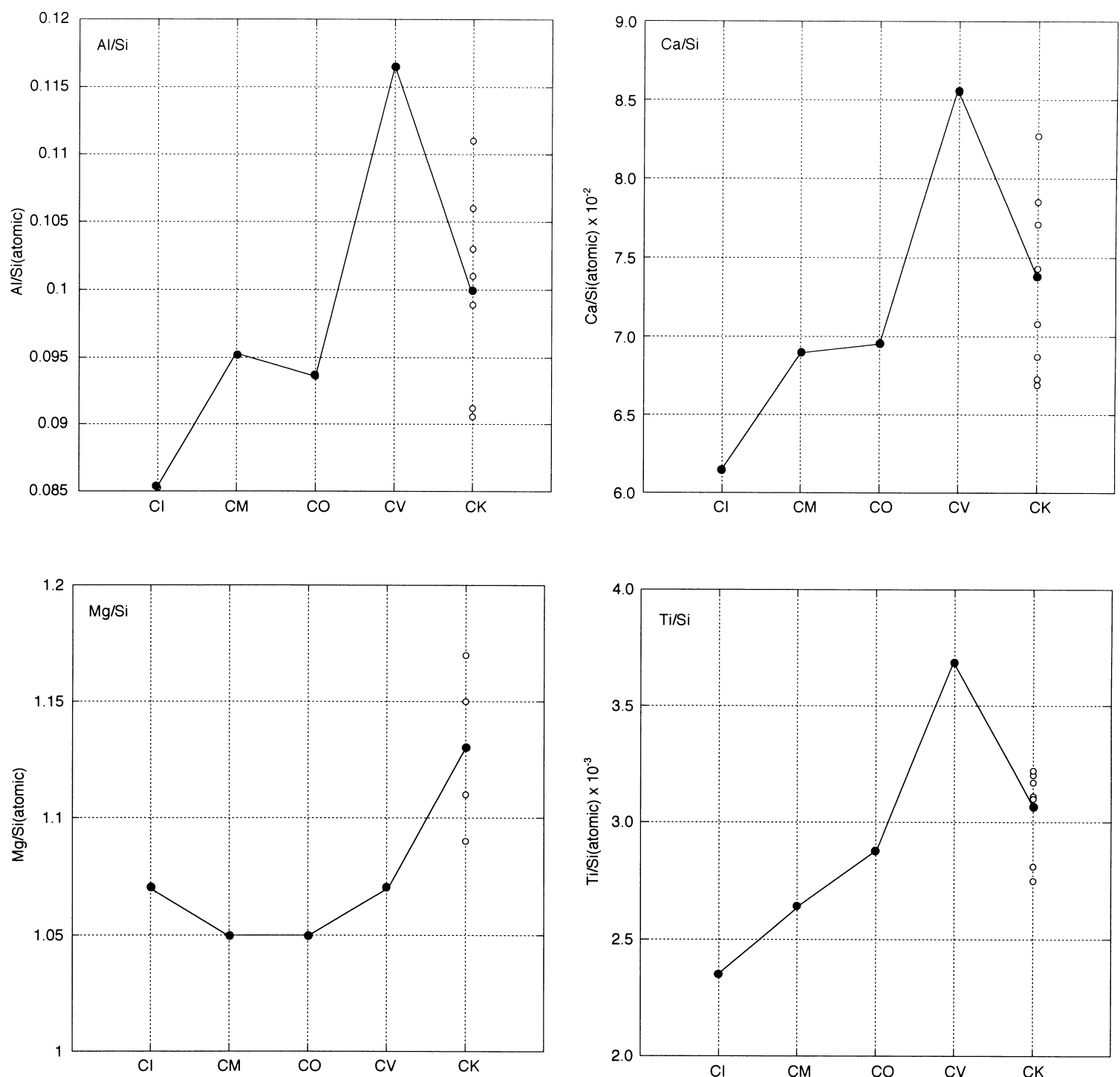

Fig. 3. Si-normalized $\mathrm{Al}, \mathrm{Ca}, \mathrm{Mg}$, and Ti ratios in carbonaceous chondrites. $\mathrm{CI}, \mathrm{CM}, \mathrm{CV}$, and $\mathrm{CO}$ values are from Wasson and Kallemeyn (1988). CK values (open circles) are from Jarosewich (1990), Wiik (1969), Nakamura et al. (2000a), and this work. Closed circles for CK indicate means of all values shown by open circles.

intervene between $\mathrm{CV}$ and $\mathrm{CM}-\mathrm{CO}$ abundances. Our data are consistent with these observations. As no Si data were obtained by INAA, the change of $\mathrm{Mg} / \mathrm{Si}$ ratios in $\mathrm{CK}$ chondrites was not discussed by Kallemeyn et al. (1991).

Sulfur, B and $\mathrm{Zn}$ abundances normalized to $\mathrm{Si}$ contents are compared for $\mathrm{CI}, \mathrm{CM}, \mathrm{CO}, \mathrm{CV}$ and CK chondrites in Fig. 4. CI values are set as unity. Data except for CK's are compiled values by
Wasson and Kallemeyn (1988). Data for CK are from this work and literature (Curtis and Gladney, 1985; McSween and Richardson, 1977; Nakamura et al., 2002). Tie lines for $\mathrm{S}$ and $\mathrm{Zn}$ end at the mean values in $\mathrm{CK}$ chondrites. In calculating a mean value for S in CK's, an anomalously low value for Maralinga was excluded. As noticed in Fig. 4, abundance patterns for $\mathrm{S}$ and $\mathrm{Zn}$ change coincidently between carbonaceous chondrites. 


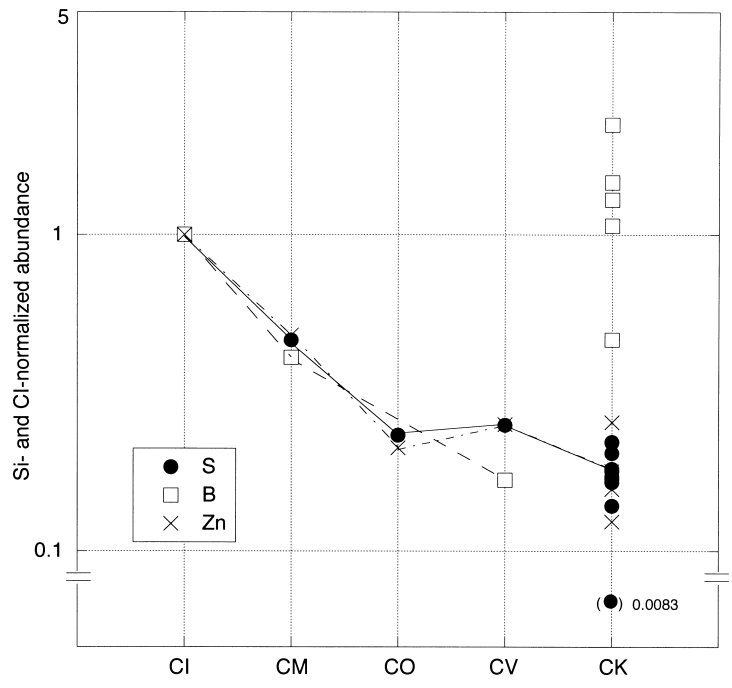

Fig. 4. Si- and CI-normalized abundance ratios of B, $S$, and $\mathrm{Zn}$ in carbonaceous chondrites. Values of $C I$, $C M, C O$, and $C V$ are compiled values by Wasson and Kallemeyn (1988). Date for CK are from Curtis and Gladney (1985), McSween and Richardson (1977), Nakamura et al. (2002), and this work.

These patterns seem to be followed by B with less certainty. Condensation temperatures for $\mathrm{S}$ and $\mathrm{Zn}$ are almost the same (648 $\mathrm{K}$ for $\mathrm{S}$ and $660 \mathrm{~K}$ for $\mathrm{Zn}$ at $10^{-4} \mathrm{~atm}$; Wai and Wasson, 1977). Condensation temperature for B is calculated to be considerably higher than those for S and $\mathrm{Zn}$ (745$759 \mathrm{~K}$ at $10^{-3} \mathrm{~atm}$; Fegley, 1993). As far as abundance data of B, S and Zn for CI, CM and CV are concerned, calculated condensation temperature for B seems to be too high. Among five groups of carbonaceous chondrites, CK's are the most depleted in $\mathrm{S}$ and $\mathrm{Zn}$.

We could determine $\mathrm{B}$ content only for the $\mathrm{E}$ fragment of Kobe. Its $\mathrm{B} / \mathrm{Si}$ ratio is $(5.3 \pm 3.3) \times$ $10^{-6}$. A large error was caused by a correction for contributions of $\mathrm{Na}$ and $\mathrm{Co}$, whose prompt gamma rays overlap with that of $\mathrm{B}$. For Kobe $\mathrm{C}$ samples, $\mathrm{B} / \mathrm{Si}$ ratio was calculated to be $5 \times 10^{-7}$ as an upper limit. Mean $\mathrm{B} / \mathrm{Si}$ ratios (in $10^{-6}$ ) for $\mathrm{CI}, \mathrm{CM}$ and $\mathrm{CV}$ carbonaceous chondrites are estimated to be 11, 4.7 and 1.9, respectively (Wasson and Kallemeyn, 1988). If we assume that $\mathrm{B} / \mathrm{Si}$ raios change similarly along with $\mathrm{S} / \mathrm{Si}$ and $\mathrm{Zn} / \mathrm{Si}$ ratios among carbonaceous chondrites, $\mathrm{B} / \mathrm{Si}$ ratios for Kobe $\mathrm{C}$ are estimated to be $2.3 \times 10^{-6}$, which is apparently lower than the observed ratio for Kobe E. Curtis et al. (1980) and Curtis and Gladney (1985) compared B concentrations in interior pieces of chondritic observed falls having known terrestrial history with those in chondritic finds having unknown terrestrial history and found that $\mathrm{B}$ contents in interior samples of falls are systematically lower that those in finds. They determined B contents for Karoonda samples with unknown terrestrial history to be $2.5 \times 10^{-5}$ and $9.0 \times 10^{-5}$ as $\mathrm{B} / \mathrm{Si}$ ratios, which are much higher than that for Kobe E. The Kobe meteorite was recovered soon after its fall, presumably suffering no terrestrial weathering. Nevertheless, the $\mathrm{B} / \mathrm{Si}$ ratio for Kobe E seems to be somewhat higher than an estimated value. The $\mathrm{B} / \mathrm{Si}$ ratio upper limit of for Kobe C samples $\left(5 \times 10^{-7}\right)$ is also smaller that the estimated value $\left(2.3 \times 10^{-6}\right)$. This suggests that $\mathrm{B}$ does not behave similarly with $\mathrm{S}$ and $\mathrm{Zn}$, with B having higher volatility than $\mathrm{S}$ and $\mathrm{Zn}$, which is contrary to the prediction by thermodynamic calculation (Fegley, 1993). As pointed out earlier, heterogeneous distribution of B in the Kobe meteorite can be an alternative explanation.

\section{Classification of carbonaceous chondrites based on PGA data}

It has been well acknowledged that individual chondrite groups have their characteristic major element compositions. Carbonaceous chondrites and ordinary chondrites are separable from each other using $\mathrm{Mg} / \mathrm{Si}, \mathrm{Al} / \mathrm{Si}$ and $\mathrm{Ti} / \mathrm{Si}$ ratios; carbonaceous chondrites have higher values of these ratios than those for ordinary chondrites, with intervening values (as atomic ratios) being 1, 0.08 and 0.02, respectively. As shown in Table $3, \mathrm{Mg}, \mathrm{Al}, \mathrm{Si}$ and Ti can be all determined by PGA with small errors due to counting statistics.

Kallemeyn et al. (1991) proposed a practical diagram for the classification of carbonaceous chondrites. On this diagram, $\mathrm{Zn} / \mathrm{Mn}$ and $\mathrm{Al} / \mathrm{Mn}$ ratios are compared by plotting these ratios on two-dimensional axes. As these three elements can be determined by INAA, $\mathrm{Zn} / \mathrm{Mn}$ vs. Al/Mn dia- 


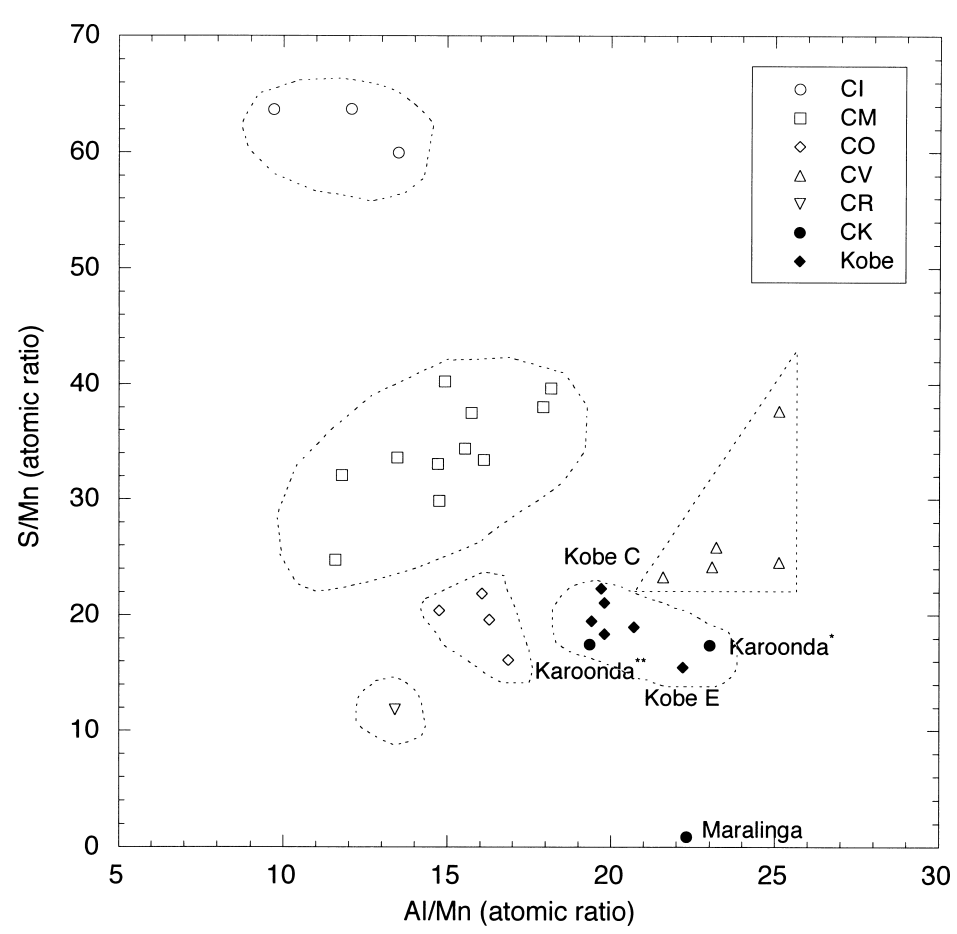

Fig. 5. S/Mn vs. Al/Mn diagram for carbonaceous chondrites. Data of Kobe and Maralinga were obtained in this work. Values for CI, CM, CO, CV, CR, and Karoonda** are from Table 4 of McSween and Richardson (1977), and those for Karoonda* and Kobe E are from Nakamura et al. (2002).

gram can potentially be widely used. In Nakamura et al. (2000a), the Kobe meteorite was classified as $\mathrm{CK}$ by using this diagram. Although INAA is non-destructive and often applied to meteorite samples to determine their chemical compositions, induced radioactivity imposes serious restrictions on the re-use of neutron-irradiated samples. PGA is methodologically like INAA, but is considerably different from INAA. As discussed by Ebihara and Oura (2001) in detail, PGA essentially does not alter chemical and isotopic compositions. The only exception is a negligibly small but detectable effect on the isotopic composition of noble gases. The residual radioactivity of samples decreases down to the same level as that of natural background after appropriate cooling. As shown in Table 2, Mn and Al contents can be sensitively determined for chondritic meteorites by PGA, but PGA has very low sensitivity for $\mathrm{Zn}$. If $\mathrm{Zn}$ can be replaced with an appropriate element with high sensitivity in PGA, a similar diagram to the $\mathrm{Zn} / \mathrm{Mn}$ vs. Al/Mn diagram can be drawn based only on PGA data. Sulfur can substitute for $\mathrm{Zn}$ because of similar behavior of $\mathrm{Zn}$ and $\mathrm{S}$ in Fig. 4. As shown in Table $3 \mathrm{a}, \mathrm{S}$ has a similarly high sensitivity to those of Mn and Si in PGA. In Fig. 5, $\mathrm{S} / \mathrm{Mn}$ ratios are plotted against $\mathrm{Al} / \mathrm{Mn}$ ratios for carbonaceous chondrites including Kobe C's. Data for Kobe C's and Maralinga are from this work and those for Kobe E and Karoonda are from Nakamura et al. (2002). The remaining data are from the literature $(\mathrm{McS}$ ween and Richardson, 1977). If a $\mathrm{Zn} / \mathrm{Mn}$ vs. Al/Mn diagram (for example, figure 5 of Kallemeyn et al. (1991)) and a S/ $\mathrm{Mn}$ vs. Al/Mn diagram (Fig. 5 of this paper) are compared, one may notice that individual groups of carbonaceous chondrites make more discrete clusters on the $\mathrm{Zn} / \mathrm{Mn}$ vs. Al/Mn diagram than those on the S/Mn vs. Al/Mn diagram. It may be noted that the $\mathrm{Zn} / \mathrm{Mn}$ vs. Al/Mn diagram quoted above was figured based on INAA data from one laboratory, whereas Fig. 5 (S/Mn vs. Al/Mn dia- 
gram) is based on data from several different laboratories, with different analytical methods being used. Nevertheless, each carbonaceous chondrite clusters with discrete locality, showing that the S/Mn vs. Al/Mn diagram can be useful for the classification of carbonaceous chondrites. In Fig. 5, Maralinga stays off the cluster of CK's. Apparently, this is caused by a loss of S, possibly due to terrestrial weathering as already discussed. Therefore, the application of the S/Mn vs. Al/Mn diagram to heavily weathered meteorites may be restricted. Considering that voluminous samples can be analyzed by PGA and that essentially no effects (including residual radioactivities) remain after PGA, we believe that PGA must be the most suitable analytical method for chemical composition of unknown materials such as new fall meteorites and returned materials by future space mission.

Acknowledgments-We thank R. Hirata for providing us the Kobe meteorite sample. We are indebted to the committee for cooperative use of JAERI facilities. Two reviewers, M. Lipschutz and T. Fukuoka, are ackowledged for their critical comments and improving English (by ML). This study is partly supported by a grant-in-aid of the Ministry of Education, Culture and Science (No. 11440167 to ME).

\section{REFERENCES}

Anders, E. and Grevesse, N. (1989) Abundances of the elements: Meteoritic and solar. Geochim. Cosmochim. Acta 53, 197-214.

Curtis, D. B. and Gladney, E. S. (1985) Boron cosmochemistry. Earth Planet. Sci. Lett. 75, 311-320.

Curtis, D., Gladney, E. and Jurney, E. (1980) A revision of the meteorite based cosmic abundance of boron. Geochim. Cosmochim. Acta 44, 1945-1953.

Ebihara, M. and Oura, Y. (2001) Applicability of prompt gamma ray analysis to the initial analysis of the extraterrestrial materials for chemical composition. Earth Planets Space 53, 1039-1045.

Ebihara, M., Oura, Y., Ishii, T., Setoguchi, M., Nakahara, H. and Otsuki, T. (2000) How effectively is the photon activation analysis applied to meteorite samples? J. Radioanal. Nucl. Chem. 244, 491496.

Fegley, B., Jr. (1993) Chemistry of the solar nebula. The Chemistry of Life's Origin (Greenberg, J. M.,
Mendoza-Gomez, C. X. and Pirronello, V., eds.), 75147, Kluwer Academic Publishers.

Grossman, J. and J. T. Wasson (1985) The origin and history of the metal and sulfide components of chondrules. Geochim. Cosmochim. Acta 49, 925-939.

Hirota, Y., Nakamura, N., Onoue, H., Misawa, K., Yamashita, K. and Wang, D. (2000) An anomalous REE component in the Kobe meteorites (abstract). Antarctic Meteorite XXV, 16-18.

Jarosewich, E. (1990) Chemical analyses of meteorites: A compilation of stony and iron meteorite analyses. Meteoritics 25, 323-337.

Jarosewich, E., Clarke, R. S., Jr. and Barrows, J. N. (1987) The Allende meteorite reference sample. Smithson. Contrib. Earth Sci. 27, 4-11.

Kallemeyn, G. W., Rubin, A. E. and Wasson, J. T. (1991) The compositional classification of chondrites: V. the Karoonda (CK) group of carbonaceous chondrites. Geochim. Cosmochim. Acta 55, 881-892.

Kato, F., Ozaki, H. and Ebihara, M. (2000) Distribution of halogens in an Antarctic ordinary chondrite. Antarct. Meteorite Res. 13, 121-134.

Kong, P. and Ebihara, M. (1997) The origin and nebular history of the metal phase of ordinary chondrites. Geochim. Cosmochim. Acta 61, 2317-2329.

Latif, S. A. (2000) Applicability of various nuclear techniques to the determination of meteorite compositions. Dr. Thesis, Tokyo Metropolitan Univ., 68 pp.

Latif, S. A., Oura, Y., Ebihara, M., Kallemeyn, G. W., Nakahara, H., Yonezawa, C., Matsue, T. and Sawahata, H. (1999) Prompt gamma ray analysis (PGA) of meteorite samples, with emphasis on the determination of Si. J. Radioanal. Nucl. Chem. 239, 577-580.

McSween, H. Y. and Richardson, S. M. (1977) The composition of carbonaceous chondrite matrix. Geochim. Cosmochim. Acta 41, 1145-1161.

Nakahara, H., Oura, Y., Sueki, K., Ebihara, M., Sato, W., Latif S. A., Tomizawa, T., Enomoto, S., Yonezawa, C. and Ito, Y. (2000) Some basic studies on non-destructive elemental analysis of bulky samples by PGAA. J. Radioanal. Nucl. Chem. 244, 405411.

Nakamura, N., Ebihara, M., Hirota, Y., Oura, Y., Yoneda, K., Kojima, H., Tomeoka, K., Kojima., T., Komura., K., Clayton, R. N., Mayeda, T. K. and Wang, D. (2000a) The Kobe meteorite: Preliminary results of bulk chemical composition, petrography, cosmic-ray induced radioactivities, oxygen isotopes an classification (abstract). Lunar Planet. Sci. 31, \#1234, Lunar and Planetary Institute, Houston (CDROM).

Nakamura, N., Kojima, H., Haramura, H., Tomeoka K., Clayton, R. N. and Mayeda, T. K. (2000b) The Kobe 
meteorite; classification and consortium studies (abstract). Antarctic Meteorites XXV, 99-101.

Nakamura, N., Oura, Y., Hirota, Y., Tomeoka, K., Kojima, H., Ebihara, M., Kojima, T., Haramura, H., Clayton, R. N., Mayeda, T. K., Misawa, K., Yamashita, K. and Yoneda, S. (2002) The KOBE (CK4) chondrite. Meteoritics Planet. Sci. (submitted).

Sueki, K., Kobayashi, K., Sato, W., Nakahara, H. and Tomizawa, T. (1996) Nondestructive determination of major elements in a large sample by prompt $\gamma$ ray neutron activation analysis. Anal. Chem. 68, 22032209.

Wai, C. M. and Wasson, J. T. (1977) Nebular condensation of moderately volatile elements and their abundances in ordinary chondrites. Earth Planet. Sci. Lett. 36, 1-13.

Wasson, J. T. (1985) Meteorites-Their Record of Early Solar System History. Freeman, New York, 267 pp.

Wasson, J. T. and Kallemeyn, G. W. (1988) Composition of chondrites. Phil. Trans. Soc. Lond. A325, 535544.
Wiik., H. B. (1969) On the regular discontinuties in the composition of meteorites. Commentat. Phys.Math. 34, 134-145.

Yonezawa, C., Wood, A. K. H., Hoshi, M., Ito, Y. and Tachikawa, E. (1993) The characteristics of the prompt gamma-ray analyzing system at the neutron beam guides of JRR-3M. Nucl. Instr. and Meth. A329, 207-216.

Zolensky, M. E., Bodnar, R. J., Gibson, E. K., Nyquist, L. E., Reese, Y., Shih, C.-Y. and Wiesmann, H. (1999) Asteroidal water within fluid inclusion-bearing halite in an H5 chondrite, Monahans (1998). Science 285, 1377-1379.

\section{APPENDiX}

Si-normalized Al, Ca, Mg, Ti, B, S, and Zn atomic abnundances in $\mathrm{CK}$ chondrites used in Figs. 3 and 4 are tabulated in Table A1. Si values are given only when they are absolutely determined.

Table A1. Relative atomic abundances in CK chondrites used in Figs. 3 and $4^{(a)}$

\begin{tabular}{|c|c|c|c|c|c|c|c|c|}
\hline Meteorites ${ }^{(\mathrm{b})}$ & $\mathrm{Mg} / \mathrm{Si}$ & $\mathrm{Al} / \mathrm{Si}$ & $\mathrm{Ca} / \mathrm{Si}$ & $\mathrm{Ti} / \mathrm{Si}$ & $\begin{array}{c}\mathrm{B} / \mathrm{Si} \\
\left(\times 10^{-5}\right)\end{array}$ & $\mathrm{S} / \mathrm{Si}$ & $\begin{array}{c}\mathrm{Zn} / \mathrm{Si} \\
\left(\times 10^{-4}\right)\end{array}$ & $\mathrm{Si}[\%]$ \\
\hline Kobe C-1 (1) & 1.17 & 0.0912 & 0.0708 & 0.0031 & & 0.0845 & & \\
\hline Kobe C-2 (1) & 1.11 & 0.0882 & 0.0743 & 0.0032 & & 0.0998 & & \\
\hline Kobe C-main (1) & 1.05 & 0.0906 & 0.0771 & 0.0031 & & 0.0829 & & \\
\hline Kobe C-4a (1) & 1.03 & 0.0868 & 0.0785 & 0.0032 & & 0.0876 & & \\
\hline Kobe C-3mix-3 (1) & 1.20 & 0.103 & 0.0669 & 0.00317 & & 0.109 & & 15.1 \\
\hline Kobe E (2) & 1.15 & 0.106 & 0.0687 & 0.00322 & 0.464 & 0.0683 & 4.07 & 16.8 \\
\hline EET87860 (3) & 1.09 & 0.101 & 0.0771 & 0.00311 & & & & 15.9 \\
\hline LEW 87009 (3) & 1.09 & 0.112 & 0.0827 & 0.00399 & & & & 16.1 \\
\hline Karoonda (4) & 1.13 & 0.0989 & 0.00673 & 0.00469 & & 0.0893 & & \\
\hline Karoonda (2) & 1.17 & 0.118 & 0.0743 & 0.00275 & 1.29 & 0.0830 & 6.64 & 15.6 \\
\hline Maralinga (2) & 1.11 & 0.111 & 0.158 & 0.00281 & 1.46 & 0.00409 & 3.23 & 15.0 \\
\hline Mean & 1.13 & 0.100 & 0.0738 & 0.00307 & 1.07 & 0.0880 & 4.65 & 15.8 \\
\hline
\end{tabular}

${ }^{(a)}$ Italic values are not used for calculating mean values.

(b)(1) This work; (2) Nakamura et al. (2002); (3) Jaroswich (1990); (4) table 4 in McSween et al. (1977) (Wiik, 1969). 